\title{
Identifying alternatives to old age psychiatry inpatient admission: an application of the balance of care approach to health and social care planning
}

\author{
Sue Tucker*, Christian Brand, Mark Wilberforce, Michele Abendstern and David Challis
}

\begin{abstract}
Background: Mental health problems in older people are common and costly, posing multiple challenges for commissioners. Against this backdrop, a series of initiatives have sought to shift resources from institutional to community care in the belief that this will save money and concurs with user preferences. However, most of this work has focused on the use of care home beds and general hospital admissions, and relatively little attention has been given to reducing the use of mental health inpatient beds, despite their very high cost.

Methods: The study employed a 'Balance of Care approach' in three areas of North-West England. This long-standing strategic planning framework identifies people whose needs can be met in more than one setting, and compares the costs and consequences of the possible alternatives in a simulation modelling exercise. Information was collected about a six-month cohort of admissions in 2010/11 $(n=216)$. The sample was divided into groups of people with similar needs for care, and vignettes were formulated to represent the most prevalent groups. A range of key staff judged the appropriateness of these admissions and suggested alternative care for those considered least appropriate for hospital. A public sector costing approach was used to compare the estimated costs of the recommended care with that people currently receive.

Results: The findings suggest that more than a sixth of old age psychiatry inpatient admissions could be more appropriately supported in other settings if enhanced community services were available. Such restructuring could involve the provision of intensive support from Care Home Outreach and Community Mental Health Teams, rather than the development of crisis intervention and home treatment teams as currently advocated. Estimated savings were considerable, suggesting local agencies might release up to $£ 1,300,000$ per annum. No obvious trade-off between health and social care costs was predicted.

Conclusions: There is considerable potential to change the mix of institutional and community services provided for older people with mental health problems. The conclusions would be strengthened by further studies and the incorporation of evidence about relative outcomes. However, the utility of the approach in challenging established patterns of resource allocation and building local ownership for change is apparent.
\end{abstract}

Keywords: UK, Health service planning, Resource allocation, Commissioning, Older people, Mental health, Balance of care, Hospital admission, Community care

\footnotetext{
* Correspondence: sue.tucker@manchester.ac.uk

Personal Social Services Research Unit, University of Manchester, Crawford House, Booth Street East, Manchester M13 9QS, UK
} 


\section{Background}

The provision of care for older people with mental health problems poses multiple challenges for commissioners $[1,2]$. Although there is recent evidence of a decline in the incidence and prevalence of dementia in developed countries [3, 4], the absolute number of people with dementia in Western Europe is anticipated to double by 2050 [5]. In addition, approximately $15 \%$ of older adults have depression [6], and still others are affected by anxiety, schizophrenia, paranoid states and substance misuse [1].

Mental health problems in old age are thus very common. They also carry high costs, both personal and economic. Many disorders are subject to relapse or of long duration, and every aspect of a person's functioning can be affected, leading to increased resource use $[1,7]$. Indeed, dementia alone is estimated to cost the UK economy $£ 23$ billion per year [8]. There is then a considerable incentive to find the most appropriate, effective and efficient ways of caring for this group.

Against this background, recent years have seen the development of a series of initiatives designed to shift resources from institutional to community care, predicated on grounds of cost-effectiveness and user preferences. However, most of these plans have focused on the use of care home and general hospital beds, and surprisingly little attention has been paid to the demand for specialist mental health inpatient services, despite their very high cost [9-11].

\section{Commissioning services for older people with mental health problems}

Following recent reform of the National Health Service (NHS), a network of over 200 Clinical Commissioning Groups are responsible for commissioning secondary and community health care for their local populations in England. Composed in part of General Practitioners, these groups control approximately two-thirds of the NHS budget. Key activities include identifying local needs, setting priorities and exercising budgetary control, encompassing fundamental decisions about the distribution of resources across different service areas, interventions and patient groups [12, 13].

Whilst the complexity of such tasks may appear selfevident, commissioning services for older people with mental health problems presents a number of special problems. These include the broad range of care delivered to this client group and the large number of (health, social, independent and voluntary sector) providers [14]. Despite increasing investment in economic evaluations, there is also a lack of evidence about the relative cost-effectiveness of institutional and non-institutional provision $[1,15]$, as most evaluations relate to specific treatments or technologies, and are of limited value to planners interested in the costs and outcomes of changes across the wider spectrum of care [16].

Such gaps highlight how important it is for commissioners to access the experience-based knowledge held by people using and providing services [17], and since the early 1990s government policy has placed increasing emphasis on engaging users in local service development $[15,18,19]$. The benefit of involving providers in the strategic planning process has perhaps had a lower profile, although this is a World Class Commissioning competency [20]. Indeed, particularly where commissioners might wish to redeploy resources, provider involvement would seem imperative, for past experience has shown that frontline clinicians will only own such changes if they have been fully involved in them. Securing their engagement is, thus, key to success $[21,22]$.

\section{The Balance of Care approach}

By way of contrast, the Balance of Care (BoC) approach offers planners, providers and commissioners a systematic framework for examining service efficiency by exploring the likely costs and outcomes of changes in the provision of community and institutional services across health and social care as part of the strategic planning process. Originally conceived of as a national policy analysis tool, the general premise is that although resources are scarce, significant amounts of money can be moved from one patient group/service to another so as to increase benefits and/or reduce costs [23, 24].

At the core of this approach is the identification of those patient groups whose needs can be met in more than one location. Hence, although it is generally accepted that for some individuals a particular care setting (e.g., a hospital bed) is the only appropriate location, the approach focuses on identifying those individuals who could be supported in more than one setting (e.g., an inpatient ward or their own home), people described as 'on the margins of care'. It then assesses the costs and consequences of the alternative options in a simulation modelling exercise, providing an empirically-based framework for challenging the existing distribution of resources. The defining characteristics of BoC studies are, thus, the identification and measurement of those patient characteristics that affect decisions about where best to support them; some means of matching people to the most appropriate care location; a specification of the resources/inputs required; and an examination of the relative costs (and ideally outcomes) of care in different settings $[25,26]$.

This pragmatic approach has many advantages for commissioners, enabling a mixture of locally relevant data, research findings and experienced practitioners' opinions to be built into the decision-making process. It accepts that health and social care planning is not wholly evidence- 
based, but provides a structured framework by which stakeholders can explore the consequences of alternative actions. It also seeks to engage providers in the planning process (building ownership), and, in focusing on patients' needs, encourages participants to look beyond existing service patterns [27]. Nevertheless, a recent systematic literature review identified just two studies that had applied the $\mathrm{BoC}$ framework specifically to the care of older people with mental health problems [28], one of which dated from the early 1990s [29], whilst the other had a relatively small sample [30]. (Further details of the underlying principles of the $\mathrm{BoC}$ approach and step-by-step accounts of the process are available elsewhere $[25,26,28]$.)

\section{The development of specialist old age psychiatry services in England}

Although the vast majority of older people with mental health problems have always been cared for in their own homes, the first specialist psychogeriatric services in England were generally hospital-based, with beds in long-stay wards and a high proportion of chronically ill patients [31]. Right from the start, however, the discipline took a community orientation reflecting the widespread closure of the asylums [32] and similar shifts in the social care sector, where a series of reforms sought to reduce the use of institutional care and expand the provision of community support including dementia-specific home and day care services and extra care housing [19, 33-35].

By the start of the 21st century localities aimed to offer comprehensive, accessible, responsive, individualised, multidisciplinary, accountable and systematic mental health care via integrated health and social care services $[19,36]$, with multidisciplinary Community Mental Health Teams (CMHTs) given a central role in providing support for people with severe or complex mental health problems in the community [37]. This was not to suggest that inpatient beds were no longer necessary, however. On the contrary, it is generally agreed that there will always be a significant minority of people who need hospital admission, with the intensive levels of assessment, monitoring and treatment this offers $[38,39]$. That said, there is considerable concern about the extent of variation in investment and practice [39, 40], for although inpatient admission can offer a safe haven, it can also be a traumatic experience, exacerbating disorientation and behavioural disturbance, and upsetting usual routines [41]. It also accounts for a large proportion of specialist mental health expenditure [42].

\section{Aims}

Against this backdrop, we undertook a BoC study to investigate the mix of services needed by older people with mental health problems in North-West England. Whilst the wider study investigated the potential for substitution between a broad range of institutional and community services, this paper focuses on the use of mental health inpatient beds, and serves as an illustration of the way in which the $\mathrm{BoC}$ approach can engage providers in the strategic planning process. It addresses the following key questions:

- Who is admitted to an acute old age psychiatry ward and why?

- Would it be possible to provide more appropriate care for some of these patients, and, if so, who needs what?

- What would this cost, and how would the cost burden change?

Although conducted in just one country, these are questions of international concern, and the planning and service delivery issues they raise are expected to have a resonance for a wider audience including commissioners, providers and policy makers across the developed world.

\section{Methods}

Building on the findings of the aforementioned systematic literature review of the past use of the $\mathrm{BoC}$ approach [28], the study applied a refined version of this tool developed by the Personal Social Services Unit over more than 15 years [30, 43, 44]. This is characterized by its firm grounding in the experience and knowledge of front line practitioners (giving validity to complex judgements about the balance of needs and resources), and utilises quantitative and qualitative methods in a sequential mixed methods design. Each of the six main elements is described below.

\section{Service user profiling}

The study was conducted in three geographical areas served by two neighbouring Trusts. Together these had population of approximately 130,000 people aged 65 plus, and a sociodemographic profile similar to England as a whole.

Data on the sociodemographic, functional, clinical and service receipt characteristics of a six month cohort of older people $(65+)$ admitted to acute mental health inpatient care were collected by nominated nursing staff shortly after admission in 2010/11. These included a number of standardised measures [45-49]. A limited amount of information was also collected at discharge, including length of hospital stay. Admissions for planned respite were excluded.

\section{Case type development}

The sample was divided into subgroups of people with similar needs for care on the basis of four variables 
deemed likely to be important in determining the locus and/or costs of their care [28]. These were: a broad grouping of primary diagnosis; a hierarchy of risk/concern capturing the main reason for admission; a classification of the extent to which individuals displayed behaviours difficult for carers to manage based on a simple additive index; and the presence or absence of a resident carer (Table 1). In combination, these generated 72 different possible sub-groups or 'case types'. The homeogeneity of the needs of the people represented by each case type was then checked, and in one instance the group was further divided according to individuals' usual place of residence, home or care home.

\section{Vignette formulation}

A series of vignettes were formulated to exemplify the most prevalent case types. These were based on real individuals and took the form of brief case histories which systematically incorporated information about the four key variables listed above as well as patients' mental health history, ability to undertake activities of daily living (ADLs), physical health, cognition, affect and support network. An example of a vignette is provided in an additional file (see Additional file 1).

\section{Alternative care planning}

Local staff from across the care continuum were invited to three care-planning workshops (one per locality) at which the most appropriate ways of meeting the needs of the people depicted in the vignettes were explored. Workshop participants were divided into small multidisciplinary

Table 1 Criteria used in the classification of case types

\begin{tabular}{ll}
\hline Dimension & Categories \\
\hline Primary diagnosis & $\begin{array}{l}\text { Organic mental health problem (most commonly } \\
\text { dementia) }\end{array}$ \\
& $\begin{array}{l}\text { Depression or anxiety } \\
\text { Other mental health problem e.g., schizophrenia }\end{array}$ \\
Main reason for & Risk of deliberate self-harm \\
admission & $\begin{array}{l}\text { Other risks i.e., self-neglect, accidental self-harm, } \\
\text { abuse/exploitation or falls, or carer stress }\end{array}$ \\
& $\begin{array}{l}\text { Behaviour management related i.e., need for } \\
\text { behaviour management, risk of harming others or } \\
\text { care breakdown }\end{array}$ \\
& $\begin{array}{l}\text { Need for diagnostic assessment, medication review } \\
\text { or treatment }\end{array}$ \\
& Low (behaviour score 0 or 1) \\
Challenging & Medium (behaviour score 2-7, typically including \\
behaviour & agitation, wandering and/or disturbed sleep) \\
& High (behaviour score 8-14, typically including \\
& resistance to care and/or aggression) \\
& Resident primary carer (including care home \\
& residents) \\
No resident carer
\end{tabular}

groups, each of which was allocated a subset of vignettes. Working individually, participants first indicated whether it was 'completely' (two points), 'possibly' (one point) or 'not' (no points) appropriate to admit each of the depicted patients to a mental health bed. The points were then totaled and the sums expressed as a percentage of the maximum possible, enabling the case types to be ranked in order of appropriateness for admission.

Working in small groups, participants then specified the care services needed to divert those case types considered least appropriate for inpatient admission from hospital care (the 'marginal case types'). For the purposes of this exercise, participants were asked to put aside short-term constraints in services and to be creative, whilst remembering that all provision inevitably has funding implications.

\section{Validation of local decision-making}

The case type ratings from the three workshops were combined, and eight acknowledged national experts in the care of older people with mental health problems were asked to review the alternative care plans for the marginal case types and to identify their preferred option. Experts were predominantly old age psychiatrists with extensive clinical and academic experience.

\section{Cost comparisons}

The estimated costs of the care plans favoured by the experts were compared with the costs of the packages of care individuals actually received immediately prior to inpatient admission. A public sector costing approach was employed, focusing on the most important (expensive or commonly incurred) costs borne by mental health and social services. Wherever possible, costs were calculated from data provided by participating agencies. If local unit costs were unavailable, figures were based on national sources [10]. The aggregate annual savings that might be achieved by substituting the preferred community arrangements for inpatient admission were then estimated, drawing on information about the yearly number of admissions in each case type and the likely length of inpatient stay. Further details of the costing exercise are provided elsewhere [50].

\section{Ethics}

Ethical approval for the study was granted by the then Cambridgeshire 3 Research Ethics Committee (reference number 10/H0306/51) and research governance procedures in each participating organisation were fulfilled. All of the information supplied to the research team for this strand of the study was fully anonymized and no contact was made with service users. As such this activity was adjudged to be a mixture of audit and service development for which service user consent was not required. 


\section{Results}

\section{Service user characteristics}

Information was collected about 216 admissions, of which the vast majority (96\%) related to people with a single admission episode in the data collection period. Of these, approximately four-fifths lived at home (about half alone and half with others), whilst the remainder lived in care homes. Table 2 details their sociodemographic, functional and clinical characteristics.

Overall, female admissions outnumbered male by three to two. More than four-fifths were under 85, and a similar proportion were nearly or completely independent in ADLs. Three-quarters were in at least fair physical health. People with a primary organic diagnosis (most commonly dementia) made up approximately two-fifths of admissions, whilst approaching half had depression or anxiety. The remainder had another functional mental health problem, such as schizophrenia. The vast majority displayed at least medium levels of challenging behaviour, and over three-quarters had at least one high level risk, highlighting the severity of their needs. Indeed, almost half were described as often agitated/restless; a similar proportion displayed at least occasional delusions/hallucinations/paranoid ideas; and still more were sometimes or often disturbed at night.

Perhaps not surprisingly, admissions from care homes were significantly older $(p=0.023)$ and more dependent $(\mathrm{p}<0.001)$ than admissions from home. They were also more likely to have an organic diagnosis $(\mathrm{p}<0.001)$, to be in worse physical health $(p=0.043)$ and to display high levels of challenging behaviour $(p=0.044)$. Further analysis of the admissions from home (own home) revealed clear differences in the profiles of people with organic and functional diagnoses (not shown). The latter

Table 2 Inpatient admissions: Sociodemographic, functional and clinical profiles by usual residence

\begin{tabular}{|c|c|c|c|c|c|c|}
\hline \multirow[t]{2}{*}{ Dimension } & \multirow[t]{2}{*}{ Categories } & \multicolumn{2}{|c|}{$\begin{array}{l}\text { Admissions from } \\
\text { home }\end{array}$} & \multicolumn{2}{|c|}{$\begin{array}{l}\text { Admissions from care } \\
\text { homes }\end{array}$} & \multirow[t]{2}{*}{$p$-value of $x^{2}$ test } \\
\hline & & $\%$ & (n) & $\%$ & (n) & \\
\hline \multirow[t]{2}{*}{ Gender } & Female & 61.2 & (109) & 54.1 & (20) & \multirow[t]{2}{*}{0.417} \\
\hline & Male & 38.8 & (69) & 45.9 & (17) & \\
\hline \multirow[t]{3}{*}{ Age } & $65-74$ & 46.6 & (82) & 22.2 & (8) & \multirow[t]{3}{*}{0.023} \\
\hline & $75-84$ & 38.6 & (68) & 52.8 & (19) & \\
\hline & $85+$ & 14.8 & (26) & 25.0 & (9) & \\
\hline \multirow[t]{4}{*}{ Activities of daily living ${ }^{a}$} & Independent & 69.3 & (124) & 24.3 & (9) & \multirow[t]{4}{*}{$<0.001$} \\
\hline & Minimal help needed & 21.8 & (39) & 43.2 & (16) & \\
\hline & Partially dependent & 5.0 & (9) & 16.2 & (6) & \\
\hline & Very/totally dependent & 3.9 & (7) & 16.2 & (6) & \\
\hline \multirow[t]{4}{*}{ General health status } & Very good/excellent & 12.6 & (22) & 2.9 & (1) & \multirow[t]{4}{*}{0.043} \\
\hline & Good & 29.1 & (51) & 31.4 & (11) & \\
\hline & Fair & 33.7 & (59) & 54.3 & (19) & \\
\hline & Poor & 24.6 & (43) & 11.4 & (4) & \\
\hline \multirow[t]{3}{*}{ Primary diagnosis } & Organic mental health problem & 31.0 & (56) & 70.3 & (26) & \multirow[t]{3}{*}{$<0.001$} \\
\hline & Depression or anxiety & 50.9 & (89) & 21.6 & (8) & \\
\hline & Other mental health problem e.g., schizophrenia & 17.2 & (30) & 8.11 & (3) & \\
\hline \multirow[t]{2}{*}{ Indicators of low mood or anxiety } & Yes & 76.2 & (125) & 68.6 & (24) & \multirow[t]{2}{*}{0.344} \\
\hline & No & 23.8 & (39) & 31.4 & (11) & \\
\hline \multirow[t]{3}{*}{ Cognition $^{a}$} & Intact/only mild impairment & 74.0 & (125) & 41.7 & (15) & \multirow[t]{3}{*}{$<0.001$} \\
\hline & Moderate impairment & 12.4 & (21) & 19.4 & (7) & \\
\hline & Severe impairment & 13.6 & (23) & 38.9 & (14) & \\
\hline \multirow[t]{3}{*}{ Challenging behaviour $^{\mathrm{a}}$} & Low & 14.0 & (25) & 2.7 & (1) & \multirow[t]{3}{*}{0.044} \\
\hline & Medium & 63.7 & (114) & 59.5 & (22) & \\
\hline & High & 22.3 & (40) & 37.8 & (14) & \\
\hline \multirow[t]{2}{*}{ Risks $^{b}$} & At least one high risk & 77.1 & (138) & 81.1 & (30) & \multirow[t]{2}{*}{0.595} \\
\hline & No high risks & 22.9 & (41) & 18.9 & (7) & \\
\hline
\end{tabular}

${ }^{a}$ Includes small proportions of imputed cases (model-based)

${ }^{\mathrm{b}}$ Includes the risk of deliberate self-harm, harming others or self-neglect 
were significantly more likely to be women $(71 \%$ vs. $44 \% ; p=0.001$ ), to be independent ( $76 \%$ vs. $54 \% ; p=$ $0.023)$ and to have indicators of low $\operatorname{mood}(82 \%$ vs. $65 \%$; $p=0.017$ ), whereas admissions with organic diagnoses displayed more challenging behaviour (40\% vs. $14 \%$ rated as high; $\mathrm{p}<0.001)$. Few differences were seen between admissions with organic diagnoses from home or care homes, albeit the latter were typically older ( $36 \%$ vs. $18 \%$ in the $85+$ age bracket; $p=0.039$ ) and more dependent $(20 \%$ vs. $7 \%$ rated as very/totally dependent; $p=0.031$ ).

\section{Reasons for inpatient admission}

An average (median) of three factors contributed to each admission (maximum eight). The most commonly cited reason for admission was the need for medication review, whilst other factors noted in at least a third of cases were the risk of self-neglect and the need for general diagnostic assessment, behavioural management or assessment of future care (Table 3). However, these were not necessarily the main reasons for admission. The most important driver for people with organic diagnoses was the need for behavioural management, closely followed by the risk of harm to others. For people with functional illnesses, the risk of self-harm and the risk of self-neglect were the top two drivers.

Table 3 Inpatient admissions: Reasons for admission by broad diagnostic group

\begin{tabular}{|c|c|c|c|c|}
\hline \multirow[t]{2}{*}{ Reason } & \multirow{2}{*}{$\begin{array}{l}\text { Organic/mixed } \\
\%(n=83)\end{array}$} & \multirow{2}{*}{$\begin{array}{l}\text { Functional } \\
\%(n=128)\end{array}$} & \multirow{2}{*}{$\begin{array}{l}\text { All } \\
\%\end{array}$} & \multirow{2}{*}{$\begin{array}{l}p \text {-value } \\
\text { of } x^{2} \text { test }\end{array}$} \\
\hline & & & & \\
\hline $\begin{array}{l}\text { At unacceptable risk of } \\
\text { deliberate self-harm }\end{array}$ & 10 & 39 & 27 & $<0.001$ \\
\hline $\begin{array}{l}\text { At unacceptable risk of } \\
\text { accidental self-harm }\end{array}$ & 16 & 11 & 13 & 0.316 \\
\hline $\begin{array}{l}\text { At unacceptable risk of } \\
\text { self-neglect }\end{array}$ & 27 & 47 & 39 & 0.003 \\
\hline $\begin{array}{l}\text { At unacceptable risk of } \\
\text { falls }\end{array}$ & 10 & 5 & 7 & 0.250 \\
\hline $\begin{array}{l}\text { At unacceptable risk of } \\
\text { harming others }\end{array}$ & 36 & 10 & 20 & $<0.001$ \\
\hline $\begin{array}{l}\text { At unacceptable risk of } \\
\text { abuse/exploitation }\end{array}$ & $5^{a}$ & 7 & 6 & 0.514 \\
\hline $\begin{array}{l}\text { For general diagnostic } \\
\text { assessment }\end{array}$ & 42 & 38 & 40 & 0.573 \\
\hline $\begin{array}{l}\text { For behaviour } \\
\text { management }\end{array}$ & 54 & 38 & 45 & 0.023 \\
\hline For review of medication & 70 & 61 & 64 & 0.185 \\
\hline For other treatment & 6 & 9 & 8 & 0.491 \\
\hline $\begin{array}{l}\text { For assessment of future } \\
\text { care needs/placement }\end{array}$ & 53 & 23 & 35 & $<0.001$ \\
\hline To relieve carer stress & 34 & 28 & 30 & 0.387 \\
\hline Other breakdown of care & 12 & 6 & 9 & 0.141 \\
\hline
\end{tabular}

${ }^{a}$ Cell size $\mathrm{n}<5$

\section{Prior service receipt}

More than six-tenths of admissions who lived at home received regular informal care, most commonly from their spouse (Table 4). The extent of this varied considerably, however, whilst less than a third had a formal social care package. As might be expected, people with dementia were significantly more likely than people with functional diagnoses to receive both informal (41\% vs. $20 \%$ receiving $21+$ hours; $p=0.030)$ and formal (15\% vs. $3 \%$ receiving an intensive care package; $p=0.017$ ) social care. By way of contrast, over seven-tenths of the sample had received at least some community mental health input prior to hospital admission, and approximately a sixth had had a previous recent inpatient stay.

\section{Case type distribution}

Of the 73 case types used to characterise the sample, 47 were populated. Together these represented $98 \%$ of the sample. As expected, some combinations of characteristics were more prevalent than others, and only those case types representing four or more admissions at the point of commencing analysis (halfway through the data collection process) were depicted in vignettes (Table 5).

Thirty-eight staff participated in the care-planning workshops, and each vignette was considered by at least 17 individuals. Nurses were the most frequently represented discipline, but other participants included consultant psychiatrists, other doctors, occupational therapists and service managers. Equal numbers of staff worked in community and inpatient settings.

Of the 17 vignettes, that representing case type 2 (people with depression or anxiety whose admission was precipitated by the risk of self-harm) was considered most appropriate for inpatient admission, with an appropriateness score of $95.4 \%$. Indeed, 20 of the 22 practitioners who rated this vignette thought the person depicted was completely appropriate for inpatient care. In contrast, no-one considered case types 26 or 31 to be definitely suitable for admission, whilst the appropriateness scores for the five case types considered least appropriate for hospital care (the marginal inpatient case types) ranged from 11.8 to $28.6 \%$. Together these captured just over $18 \%$ of admissions. Three predominantly or exclusively represented people admitted from home (6, 10 and 28a), and two admissions from care homes (26 and 31). The need for behavioural management was the main reason for admission in three of the five types $(10,26$ and $28 a)$.

\section{Proposed care plans}

Ten different care packages were proposed for the marginal case types, ranging from one for case type 31 to three for case type 6, dependent on both the number of participating groups in each locality and the case types 
Table 4 Inpatient admissions from home: Formal and informal support prior to admission

\begin{tabular}{|c|c|c|c|c|c|c|}
\hline \multirow[b]{2}{*}{ Dimension } & \multirow[b]{2}{*}{ Categories } & \multicolumn{2}{|c|}{ Organic/mixed diagnosis } & \multicolumn{2}{|c|}{ Functional diagnosis } & \multirow[t]{2}{*}{$p$-value of $x^{2}$ test } \\
\hline & & $\%$ & (n) & $\%$ & (n) & \\
\hline \multirow[t]{4}{*}{ Informal care } & None & 29.6 & (16) & 46.9 & (52) & 0.030 \\
\hline & 1-7 hours per week & 13.0 & (7) & 17.1 & (19) & \\
\hline & 8-20 hours per week & 16.7 & (9) & 16.2 & (18) & \\
\hline & $21+$ hours per week & 40.7 & (22) & 19.8 & (22) & \\
\hline \multirow[t]{3}{*}{ Main informal carer ${ }^{a}$} & Spouse & 65 & (26) & 49.2 & (30) & 0.244 \\
\hline & Child (including children-in-law) & 30 & (12) & 39.3 & (24) & \\
\hline & Other & 5 & (2) & 11.5 & (7) & \\
\hline \multirow[t]{2}{*}{ Lives with main informal carer ${ }^{a}$} & Yes & 74.4 & (29) & 59.3 & (35) & 0.126 \\
\hline & No & 25.6 & (10) & 40.7 & (24) & \\
\hline \multirow[t]{2}{*}{ Nature of informal support ${ }^{a}$} & Personal and/or physical & 60.7 & (17) & 30.4 & (17) & 0.008 \\
\hline & Other practical help & 39.3 & (11) & 69.6 & (39) & \\
\hline \multirow[t]{4}{*}{ Formal social support ${ }^{\mathrm{b}}$} & None or very minor & 53.9 & (21) & 76.8 & (76) & 0.017 \\
\hline & Intermittent & 12.8 & (5) & 10.1 & (10) & \\
\hline & Limited care package & 18.0 & (7) & 10.1 & (10) & \\
\hline & Intensive care package & 15.4 & (6) & 3.0 & (3) & \\
\hline \multirow[t]{2}{*}{ CMHT input } & Yes & 79.0 & (45) & 68.7 & (79) & 0.158 \\
\hline & No & 21.1 & (12) & 31.3 & (36) & \\
\hline \multirow[t]{2}{*}{ Recent mental health admission } & Yes & 20.4 & (11) & 18.2 & (20) & 0.737 \\
\hline & No & 79.6 & (43) & 81.8 & (90) & \\
\hline
\end{tabular}

a Based on applicable cases (i.e., those that received at least one hour of informal care)

b Intermittent input less than daily, mainly outside the home; Limited care package 1-9 hours personal care/domestic help/sitting service combined or seven or more meals per week; Intensive care package $\geq 10$ hours personal care/domestic help/sitting service combined per week

Table 5 Characteristics of the 17 inpatient case types depicted in the vignettes

\begin{tabular}{|c|c|c|c|c|c|}
\hline Case type & Broad diagnosis & Main reason for admission & Challenging behaviour & Resident carer & \% Appropriateness score \\
\hline 1 & Depression/anxiety & Risk of deliberate self-harm & Low & Yes & 73.8 \\
\hline 2 & Depression/anxiety & Risk of deliberate self-harm & Low & No & 95.4 \\
\hline 3 & Depression/anxiety & Risk of deliberate self-harm & Medium & Yes & 56.0 \\
\hline 4 & Depression/anxiety & Risk of deliberate self-harm & Medium & No & 78.9 \\
\hline 6 & Depression/anxiety & Other risks & Medium & Yes & 26.2 \\
\hline 7 & Depression/anxiety & Other risks & Medium & No & 54.4 \\
\hline 9 & Depression/anxiety & Behaviour management related & Medium & Yes & 48.0 \\
\hline 10 & Depression/anxiety & Behaviour management related & Medium & No & 28.3 \\
\hline 16 & Depression/anxiety & Assessment/treatment/check medication & Medium & No & 33.3 \\
\hline 21 & Organic & Other risks & Medium & Yes & 35.7 \\
\hline 22 & Organic & Other risks & Medium & No & 41.3 \\
\hline 26 & Organic & Behaviour management related & Medium & Yes & 23.8 \\
\hline $28 a^{a}$ & Organic & Behaviour management related & High & Yes & 28.6 \\
\hline $28 b^{a}$ & Organic & Behaviour management related & High & Yes & 53.8 \\
\hline 29 & Organic & Assessment/treatment/check medication & Medium & Yes & 50.0 \\
\hline 31 & Organic & Assessment/treatment/check medication & High & Yes & 11.8 \\
\hline 40 & Other & Behaviour management related & Medium & Yes & 44.4 \\
\hline
\end{tabular}

${ }^{\mathrm{a}}$ People in case types $28 \mathrm{a}$ and $28 \mathrm{~b}$ were admitted from home and care homes respectively 
they deemed marginal. Each of the three plans for the two case types depicting care home residents involved input from a specialist care home support team, whilst those for people admitted from home drew on an intensive mix of primary care and mental health expertise, including frequent mental health support worker input to assist people with their diet, medication, personal and social care needs. The need for a carer's assessment with a view to the provision of ongoing support and assistance was also highlighted.

\section{Cost comparisons}

Table 6 compares the estimated weekly costs of the community care arrangements proposed by the experts with those of the care patients actually received prior to inpatient admission. In order to compare like with like, only those individuals who lived in the care setting described in the vignette are included in this and the following analyses (i.e., the care home residents represented by case types 26 and 31 and the people at home represented by case types 6,10 and 28a). Gaps in the data on actual service receipt mean the numbers in this table are small. However, two things are striking: the very high degree of variation in actual service costs within case types; and the extent to which the estimated costs of the recommended care packages exceed the median costs of actual service receipt. Indeed, in all bar one case the former are at least double the latter.

In Table 7, the weekly costs of the recommended community care packages are then compared with those of inpatient care, highlighting the very high costs of hospital support. Thus, although the suggested packages were considerably more expensive than the community care people actually received, they were substantially lower than the costs of hospital admission. Furthermore, despite the fact that the recommended care packages often involved multiple staff and intensive input, the vast majority of this difference was attributable to the relatively low costs of providing specialist mental health care in the community as opposed to in hospital. Social care costs were relatively low in both scenarios.

Finally, Fig. 1 shows the potential aggregate savings that might be achieved if it proved possible to divert some or all of these admissions for a year. The key variables in these calculations are: $i$ / the number of patients represented by each case type over a 12-month period; ii/ the number of inappropriate admissions they would be expected to experience over a year; iii/ the average length of inpatient stay for each case type; and iv/ the number of days the alternative intensive community care packages would need to be employed. The first three of these variables are based on information from the service user profiling exercise, and the latter on information from the alternative care planning exercise. Thus if, for example, it proved possible to prevent all 20 of the admissions projected to be experienced by people in case type 26 over the course of a year, with each prevented admission releasing $£ 18,813$ from an average 62-day hospital stay, this could potentially amount to $£ 376,260$ per year. Indeed, assuming it was possible to divert all the patients in all five case types, local agencies might incur savings in the region of $£ 1,300,000$ (the difference between a $100 \%$ diversion success rate and a $0 \%$ diversion success rate), whilst even if it only proved possible to divert $50 \%$ of each case type, savings of $£ 680,000$ could be attained. Diverting the care home residents represented by case types 26 and 31 could of itself potentially release $£ 526,000$.

\section{Discussion}

The desire to curb rising health care costs has longpreoccupied many nations [16]. Against a background of increasing demand, the 2012 audit of investment in older people's mental health services in England brings the scale of this challenge into focus, reporting a $3.1 \%$ fall in real-term funding from the previous year [42]. This raises a number of important issues for local decisionmakers, two of which have been addressed in the present work: the desire to prevent unnecessary hospital admissions and the determination of the optimal service mix.

Table 6 Marginal inpatient case types: Estimated weekly costs of community care ${ }^{a}$ and extent of informal care

\begin{tabular}{|c|c|c|c|c|c|c|c|c|c|}
\hline $\begin{array}{l}\text { Case type } \\
\text { (setting) }^{b}\end{array}$ & $\begin{array}{l}\text { Number in } \\
\text { setting }\end{array}$ & $\begin{array}{l}\text { Number for } \\
\text { whom have } \\
\text { information } \\
\text { on services }\end{array}$ & $\begin{array}{l}\text { Median cost of } \\
\text { actual care }\end{array}$ & $\begin{array}{l}\text { Mean cost of } \\
\text { actual care }\end{array}$ & $\begin{array}{l}\text { Standard } \\
\text { deviation }\end{array}$ & $\begin{array}{l}\text { Min - max cost } \\
\text { of actual care }\end{array}$ & $\begin{array}{l}\text { Cost of } \\
\text { recommended } \\
\text { care }\end{array}$ & $\begin{array}{l}\text { Number } \\
\text { receiving } \\
\text { any } \\
\text { informal } \\
\text { care }\end{array}$ & $\begin{array}{l}\text { Number } \\
\text { receiving } \\
21+\text { hours } \\
\text { informal } \\
\text { care per } \\
\text { week }\end{array}$ \\
\hline $6(H)$ & 8 & 5 & 192 & 216 & 236 & $0-600$ & 561 & 6 & 2 \\
\hline $10(\mathrm{H})$ & 4 & 4 & 137 & 247 & 328 & $0-714$ & 260 & 1 & 0 \\
\hline $26(\mathrm{CH})$ & 10 & 5 & 57 & 228 & 280 & $11-619$ & 211 & N/A & N/A \\
\hline $28(H)$ & 14 & 7 & 36 & 163 & 328 & $0-900$ & 269 & 11 & 7 \\
\hline $31(\mathrm{CH})$ & 3 & 2 & 70 & 70 & 100 & $0-141$ & 517 & N/A & N/A \\
\hline
\end{tabular}

as per patient

${ }^{\mathrm{b}} \mathrm{H}=$ home; $\mathrm{CH}=$ care home 
Table 7 Marginal inpatient case types: Estimated weekly costs of inpatient and recommended community care ${ }^{a}$ by cost sector

\begin{tabular}{llllll}
\hline $\begin{array}{l}\text { Case } \\
\text { type } \\
\text { (setting) }^{b}\end{array}$ & Inpatient care & \multicolumn{3}{c}{$\begin{array}{l}\text { Recommended } \\
\text { community care }\end{array}$} & $\begin{array}{l}\text { Total cost } \\
\text { difference }\end{array}$ \\
& $\begin{array}{l}\text { NHS mental } \\
\text { health costs }\end{array}$ & $\begin{array}{l}\text { SSD } \\
\text { costs }\end{array}$ & $\begin{array}{l}\text { NHS mental } \\
\text { health costs }\end{array}$ & $\begin{array}{l}\text { SSD } \\
\text { costs }\end{array}$ \\
\hline $6(\mathrm{H})$ & 2,193 & 73 & 442 & 119 & -1704 \\
$10(\mathrm{H})$ & 2,193 & 73 & 260 & 0 & -2005 \\
$26(\mathrm{CH})$ & 2,193 & 73 & 186 & 24 & -2055 \\
$28(\mathrm{H})$ & 2,193 & 73 & 155 & 115 & -1996 \\
$31(\mathrm{CH})$ & 2,193 & 145 & 508 & 9 & -1821 \\
\hline
\end{tabular}

ass per patient. Adjusted weekly costs i.e., one-off components have been distributed over the median length of inpatient admission for each case type ${ }^{\mathrm{b}} \mathrm{H}=$ home; $\mathrm{CH}=$ care home

${ }^{\mathrm{C}}$ Recommended option minus original option

Although previous studies have typically suggested that up to thirty per cent of adult mental health admissions may be inappropriate, this body of work is now several years old [51]. Moreover, little research has specifically explored the use of old age mental health beds. One point prevalence survey of older inpatients in the mid 1990s concluded that nearly a quarter no longer required acute hospital care [52]. However, community provision and admission thresholds are likely to have changed since then, whilst the authors did not consider how appropriate or necessary admission was in the first place. The fact that local practitioners in the current study had serious reservations about the appropriateness of more than a sixth of admissions is thus a significant finding, reinforcing the findings of the smaller BoC study mentioned above [30]. It is, however, important to note that these results do not automatically imply that current placement decisions are being made incorrectly, for these will have been constrained by the availability of alternative care. Rather, the findings identify the potential to divert a proportion of hospital admissions given an improved service mix, and provide commissioners with information on the needs and characteristics of those case types on whom any attempt to reduce the use of hospital beds might first focus. They also provide data on the mix of services necessary to effect such change.

With regard to the latter, the study suggests (perhaps surprisingly) that, at least for patients admitted from home, this would not necessarily require the development of new or innovative services, but rather more 'standard care', including intensive CMHT and primary care input. Indeed, most if not all of the proposed services were already available in the study catchment area, albeit they were often time-limited (support worker input), closed at weekends (CMHTs) or difficult to access. This desire to strengthen established services sits in contrast with growing calls for the development of a network of crisis resolution and home treatment services for older people [38, 39], emulating provision for working age adults [53]. Such services aim to provide an alternative to hospital admission by "intervening in the pathway between community-based referrers and inpatient care, providing robust assessment and gatekeeping of admissions" and typically operate a 24-hour service that seeks to resolve crises in people's own homes ([54], p375). A recent report on adult mental health service development, however, noted that the creation of specialist teams with different access criteria can be confusing for referrers and lead to patients being passed from service to service [32]. Furthermore, there is as yet little robust evidence that crisis resolution and home treatment teams for older people with mental health problems can reduce hospital admissions, although feedback from early exemplars suggests a degree of perceived effectiveness [55].

Conversely, local staff perceived the development of specialist care home outreach as critical to the prevention of inappropriate admissions from care homes. Such services were seen to have the potential to undertake detailed behavioural and functional assessments that could act as the basis for person-centred interventions, and to serve as a single point of reference and support for care home staff. The external experts also stressed the relative advantage of such teams over the input of multiple professionals from different organisations, whilst whatever form such provision takes, an advantage of focusing on this client group is that the resources employed in preventing one admission should also prevent future admissions as care home staff gain skills and knowledge.

Whilst the results are encouraging in highlighting the potential for change, there are a number of reasons to treat the reported figures with caution. First, it should be noted that the given costs are all estimates (albeit sensitivity analysis suggested that even allowing for considerable uncertainty in the quantity and cost of resources, the general picture remained unchanged i.e., the cost of inpatient care was significantly higher that of the proposed community alternatives). Second, in considering only public expenditure, the study will have significantly underestimated the real costs to society of supporting people at home, including the costs of the substantial assistance provided by informal carers. Third, although the analysis identified a number of potentially inappropriate admissions to hospital, no information was collected about the extent of unmet demand. It is thus possible that other people, currently supported in the community, might be more appropriately admitted to hospital. Fourth, as in other BoC analyses, no account was taken of the need for parallel funding whilst community services are developed, a key ingredient in changing service provision. Fifth, in order to release significant savings, the number of hospital admissions prevented would need to reach a critical mass, 


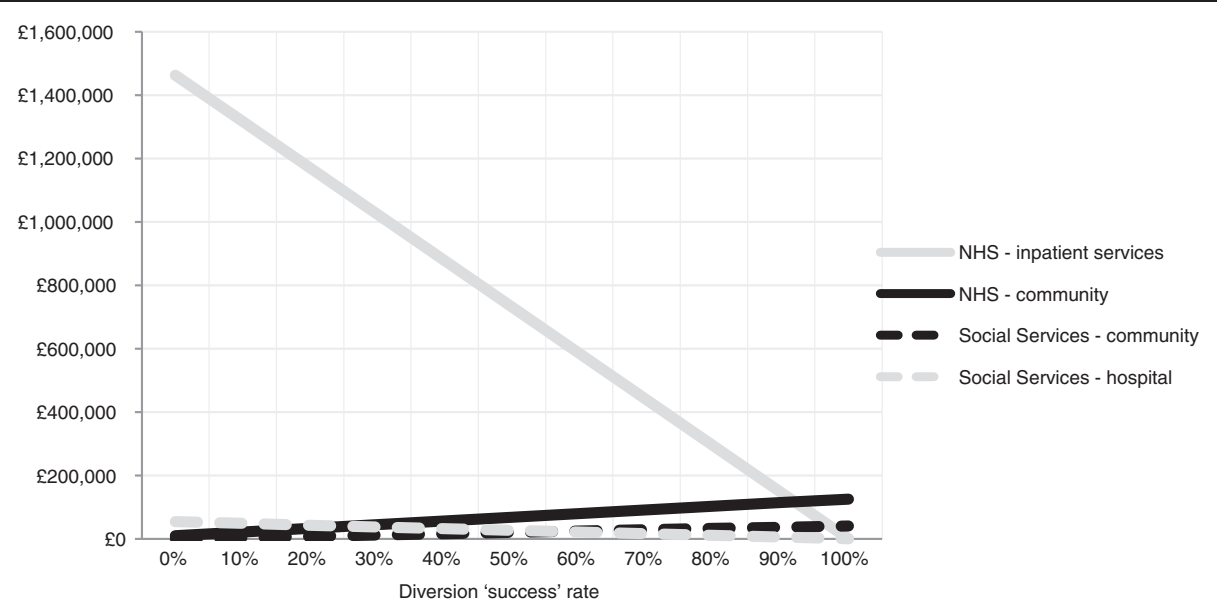

Fig. 1 Marginal inpatient case types: The effect on different cost types of different diversion rates ( $£$ s per year)

so as to facilitate the closure of beds or wards. Indeed, it is not clear that even if it proved possible to prevent all 39 marginal admissions in this study, this crucial threshold would be reached, particularly given that the study was conducted across two Trusts. That said, the same organisations' mental health services for working age adults already share wards, and the decision to focus the analysis on the five least appropriate case types for admission was a relatively conservative one, with the existence of two additional case types with appropriateness scores of less than 40 indicating the potential for local decision-makers to be more ambitious if so desired.

Finally it should be noted that although the mix of services available in the study area and the demographic and clinical characteristics of the patient population appeared typical of provision nationwide [50], it is not clear to what extent this study's findings can be generalised to other localities. There is thus a need for further BoC studies to be undertaken in a wider variety of areas. These should, ideally, utilise a full social costings approach, whilst the design would also be strengthened by the incorporation of robust evidence about the relative outcomes of marginal patients supported in different settings. In the light of this gap, the current study assumed that staff's decisions about appropriate care were "predicated by assumptions about what outcomes are desired" ([56], p9). However, this does not diminish the need for controlled comparisons.

\section{Conclusions}

This study details the needs and number of older people admitted to acute old age psychiatry beds in three areas of North-West England (key information for local commissioners) and highlights the potential for change. The results suggest that if enhanced community services were available, a significant minority of inpatients could be more appropriately supported in their own homes at a cost considerably lower than that currently incurred. Furthermore, such a shift would not precipitate any obvious trade-off between health and social care costs, but the substitution of intensive specialist mental health care in the community for current inpatient treatment.

Writing more than 15 years ago, Wistow [57] noted that the need to improve efficiency can provide a powerful incentive to reshape services where this appears to be a cost effective strategy. Nevertheless, in practice, the reconfiguration of services is more often informed by historical precedent and government policy than by evidence on costs or effectiveness $[56,58]$. In this situation, the BoC approach, which allows local decision-makers to systematically explore the costs and consequences of different courses of action, facilitating dialogue between diverse providers and supporting informed decision-making reflecting local judgements [59], appears to have much utility.

\section{Additional file}

Additional file 1: Example of a vignette.

\section{Abbreviations}

ADLs: Activities of daily living; BoC: Balance of care; CMHT: Community mental health team; NHS: National Health Service.

\section{Competing interests}

The authors declare that they have no competing interests.

\section{Authors' contributions}

ST participated in the design and coordination of the study, co-led the care-planning workshops, helped with the cost analysis, and drafted the manuscript. CB participated in the design of the study, undertook the statistical and cost analysis, and helped to draft the manuscript. MW participated in the design of the study, co-led the care-planning workshops and helped to draft the manuscript. MA participated in the design of the study, assisted with the care-planning workshops, and helped to draft the manuscript. DC conceived of the study, participated in the design and coordination of the study and helped to draft the manuscript. All authors read and approved the final manuscript. 


\section{Acknowledgements}

This article presents independent research commissioned by the National Institute for Health Research (NIHR) under its Programme Grants for Applied Research scheme (RP-PG-0606-1109). The views expressed in this publication are those of the authors and not necessarily those of the NHS, the NIHR or the Department of Health.

The authors would like to thank Dr Hilde Verbeek for her assistance with the formulation of the vignettes and the care-planning workshops.

\section{Received: 28 November 2014 Accepted: 8 June 2015}

\section{Published online: 17 July 2015}

\section{References}

1. Draper B, Low L. What is the effectiveness of old age mental health services? [http.//www.euro.who.int/document/E83685.pdf]

2. World Health Organization. The Global Burden of Disease: 2004 update. Geneva: WHO Press; 2008.

3. Matthews FE, Arthur A, Barnes J, Bond J, Jagger C, Robinson L, et al. A two-decade comparison of prevalence of dementia in individuals aged 65 years and older from three geographical areas of England: results of the Cognitive Function and Ageing Study I and II. Lancet. 2013;382:1405-12.

4. Qiu C, von Strauss E, Bäckman L, Winblad B, Fratiglioni L. Twenty-year changes in dementia occurrence suggest decreasing incidence in central Stockholm, Sweden. Neurol. 2013;80:1888-94.

5. Alzheimer's Society. Cases of dementia to double in Western Europe by 2050 [http://www.alzheimers.org.uk/site/scripts/press_article.php?pressReleaselD=1064]

6. Beekman ATF, Copeland JRM, Prince MJ. Review of community prevalence of depression in later life. Br J Psychiatry. 1999;174:307-11.

7. Wimo A, Karlsson G, Winblad B. Health economic aspects of dementia. In: Burns A, O'Brien J, Ames D, editors. Dementia. London: Hodder Arnold; 2005. p. 136-46.

8. Luengo-Fernandez R, Leal J, Gray A. Dementia 2010: The Economic Burden of Dementia and Associated Research Funding in the United Kingdom. Cambridge: Alzheimer's Research Trust; 2010.

9. Cahill S, O'Shea E, Pearce M. Creating Excellence in Dementia Care. A research review for Ireland's dementia strategy. Dublin and Galway: Trinity College and National University of Ireland; 2012

10. Curtis L. Unit Costs of Health and Social care 2011. Canterbury: Personal Social Services Research Unit, University of Kent; 2011.

11. Philp I, Mills KA, Thanvi B, Ghosh K, Long JF. Reducing hospital bed use by frail older people: results from a systematic review of the literature. Int $\rfloor$ Integr Care, 2013. [http://www.ncbi.nlm.nih.gov/pmc/articles/PMC3860583/]

12. Health and Social Care Act (2012). [http://www.legislation.gov.uk/ukpga/ 2012/7/contents/enacted]

13. Naylor C, Curry N, Holder H, Ross S, Marshall L, Tait E. Clinical Commissioning groups. Supporting Improvement in General Practice? London: King's Fund; 2013.

14. Forte $\mathrm{P}$, Bowen T. Services for older people: Finding a balance. In: Vissers $\mathrm{JMH}$, Beech R, editors. Health Operations Management. London: Routledge; 2005. p. 282-304.

15. Goodchild C. Living well with Dementia. The National Dementia Strategy. Joint Commissioning Framework for Dementia. London: Department of Health; 2009.

16. Williams I, Robinson S. Decision making and priority setting. In: Glasby J, editor. Commissioning for Health and well-being. Bristol: Policy Press; 2012. p. 63-84.

17. Glasby J, Beresford P. Who knows best? Evidence-based practice and the service user contribution. Crit Soc Policy. 2006;26:268-84.

18. Department of Health. Implementing Caring for People, EL(93)18. London: Department of Health; 1993.

19. Department of Health. National Service Framework for Older People. London: Department of Health; 2001.

20. Department of Health. World Class Commissioning: Vision Summary. London: Department of Health; 2007.

21. Peacock SJ, Mitton C, Ruta D, Donaldson C, Bate A, Hedden L. Priority setting in healthcare: Towards guidelines for the programme budgeting and marginal analysis framework. Expert Rev of Pharmacoecon Outcomes Res. 2010;10:539-52.

22. Royal College of Physicians. Hospitals on the Edge? The Time for Action. London: Royal College of Physicians; 2012
23. McDonald AG, Cuddeford GC, Beale EML. Balance of care: Some mathematical models of the National Health Service. Br Med Bull. 1974;30:262-71.

24. Arthur Andersen and Company. A User's Guide to the Balance of Care Report: Non-Technical user Manual, 1. London: DHSS; 1981.

25. Mooney GH. Planning for balance of care of the elderly. Scott J Polit Econ. 1978;25:149-64.

26. Hughes J, Challis DJ. Frail older people - margins of care. Rev Clin Gerontol. 2004;14:155-64.

27. Forte P. Needs-led planning for community care: the balance of care approach In: Gould N, Moultrie K, editors. Effective Policy, Planning and Implementation. Bath: Social Services Research and Development Unit; 1997. p. 66-73.

28. Tucker S, Brand C, Wilberforce M, Challis D. The balance of care approach to health and social care planning: Lessons from a systematic literature review. Health Serv Manage Res. 2013;26:18-28.

29. Kavanagh S, Schneider J, Knapp M, Beecham J, Netten A. Elderly people with cognitive impairment: Costing possible changes in the balance of care. Health Soc Care Community. 1993;1:69-80.

30. Tucker S, Hughes J, Burns A, Challis D. The balance of care: reconfiguring services for older people with mental health problems. Aging Ment Health. 2008;12:81-91.

31. Wattis J, Wattis L, Arie T. Psychogeriatrics: A national survey of a new branch of psychiatry. BMJ. 1981;282:1529-33.

32. Gilburt H, Peck E, Ashton B, Edwards N, Naylor C. Service Transformation. Lessons from Mental Health. London: King's Fund; 2014

33. Commission A. Forget Me Not: Mental Health Services for Older People. London: Audit Commission; 2000

34. Challis D. The effectiveness of community care. Rev Clin Gerontol. 1993:3:97-104.

35. Department of Health. Caring for People, Community Care in the Next Decade and Beyond. London: HMSO; 1989

36. Burns A, Dening T, Baldwin R. Care of older people: Mental health problems. Br Med J. 2001;322:789-91

37. Lingard J, Milne A. Integrating Older People's Mental Health Services: Community Mental Health Teams for Older People. London: Department of Health; 2004.

38. Joint Commissioning Panel for Mental Health. Guidance for Commissioners of Older People's Mental Health Services. London: Joint Commissioning Panel for Mental Health; 2013.

39. Pinner G, Hiller J, Branton T, Ramakrishnan A. In-Patient Care for Older People within Mental Health Services. London: Royal College of Psychiatry; 2011

40. Banerjee S. Organisation of old age psychiatry services. Rev Clin Gerontol 1998:8:217-25.

41. Fottrell E. Acute psychogeriatric assessment wards: The case against Geriatr Med. 1996;26:19-21.

42. Strategies MH. 2011/12 National Survey of Investment in Mental Health Services for Older People. London: Department of Health; 2012. p. 2012.

43. Challis D, Hughes J. Frail old people at the margins of care: Some recent research findings. Br J Psychiatry. 2002;180:126-30.

44. Clarkson P, Hughes J, Challis D. The potential impact of changes in public funding for residential and nursing home care in the United Kingdom: The Residential Allowance. Ageing Soc 2005:25:159-80.

45. Folstein MF, Folstein SE, McHugh PR. "Mini-mental state". A practical method for grading the cognitive state of patients for the clinician. J Psychiatr Res. 1975;12:189-98.

46. Kroenke K, Spitzer RL, Williams J. The Patient Health Questionnaire-2: Validity of a Two-Item Depression Screener. Med Care. 2003:41:1284-92.

47. Mahoney Fl, Barthel DW. Functional evaluation: the Barthel Index: a simple index of independence useful in scoring improvement in the rehabilitation of the chronically ill. Rehabil. 1965;4:61-5.

48. Morris JN, Fries BE, Mehr DR, Hawes C, Phillips C, Mor V et al. MDS Cognitive Performance Scale. J Gerontol. 1994;49:M174-82.

49. Yesavage JA, Brink TL, Rose TL, Lum O, Huang V, Adey MB, et al. Development and validation of a geriatric depression screening scale: A preliminary report. J Psychiatr Res. 1983:17:37-49.

50. Challis D, Tucker S, Wilberforce M, Brand C, Abendstern M, Stewart K, et al. National trends and local delivery in old age mental health services: towards an evidence base. A mixed-methodology study of the balance of care approach, community mental health teams and specialist mental health outreach to care homes. Programme Grants Appl Res. 2014;02:04. 
51. McDonagh MS, Smith DH, Goddard M. Measuring appropriate use of acute beds: A systematic review of methods and results. Health Policy. 2000;53:157-84.

52. Koffman J, Fulop NJ, Pashley D, Coleman K. No way out: The delayed discharge of elderly mentally ill acute and assessment patients in North and South Thames Regions. Age Ageing. 1996;25:268-72.

53. Department of Health. National Service Framework for Mental Health. London: Department of Health; 1999.

54. Onyett S, Linde K, Glover G, Floyd S, Bradley S, Middleton H. Implementation of crisis resolution / home treatment teams in England: national survey 2005-2006. Psychiatr Bull. 2008:32:374-7.

55. Toot S, Devine M, Orrell M. The effectiveness of crisis resolution/home treatment teams for older people with mental health problems: a systematic review and scoping exercise. Int J Geriatr Psychiatry. 2011;26:1221-30.

56. Bebbington A, Turvey K, Janzon K. Needs Based Planning for Community care. PSSRU discussion paper 1206/2. Canterbury: PSSRU, University of Kent at Canterbury; 1996

57. Wistow G. Decentralisation from acute to home care settings in England Health Policy. 1997;41(Supplement):91-108.

58. Goodwin E, Frew E, Using programme budgeting and marginal analysis (PBMA) to set priorities. Reflections from a qualitative assessment in an English Primary Care Trust. Soc Sci Med. 2013;98:62-168.

59. Barlow J, Bayer S. Raising the profile of simulation and modelling in health services planning and implementation. J Health Serv Res Policy. 2011;16:129-30

\section{Submit your next manuscript to BioMed Central and take full advantage of:}

- Convenient online submission

- Thorough peer review

- No space constraints or color figure charges

- Immediate publication on acceptance

- Inclusion in PubMed, CAS, Scopus and Google Scholar

- Research which is freely available for redistribution 